\title{
Competition, Market Structure, and Bid-Ask Spreads in Stock Option Markets
}

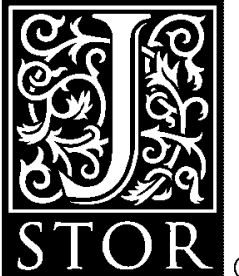

Stewart Mayhew

The Journal of Finance, Vol. 57, No. 2. (Apr., 2002), pp. 931-958.

Stable URL:

http://links.jstor.org/sici?sici=0022-1082\%28200204\%2957\%3A2\%3C931\%3ACMSABS\%3E2.0.CO\%3B2-V

The Journal of Finance is currently published by American Finance Association.

Your use of the JSTOR archive indicates your acceptance of JSTOR's Terms and Conditions of Use, available at

http://www.jstor.org/about/terms.html. JSTOR's Terms and Conditions of Use provides, in part, that unless you have obtained prior permission, you may not download an entire issue of a journal or multiple copies of articles, and you may use content in the JSTOR archive only for your personal, non-commercial use.

Please contact the publisher regarding any further use of this work. Publisher contact information may be obtained at http://www.jstor.org/journals/afina.html.

Each copy of any part of a JSTOR transmission must contain the same copyright notice that appears on the screen or printed page of such transmission.

The JSTOR Archive is a trusted digital repository providing for long-term preservation and access to leading academic journals and scholarly literature from around the world. The Archive is supported by libraries, scholarly societies, publishers, and foundations. It is an initiative of JSTOR, a not-for-profit organization with a mission to help the scholarly community take advantage of advances in technology. For more information regarding JSTOR, please contact support@ jstor.org. 


\title{
Competition, Market Structure, and Bid-Ask Spreads in Stock Option Markets
}

\author{
STEWART MAYHEW*
}

\begin{abstract}
This paper examines the effects of competition and market structure on equity option bid-ask spreads from 1986 to 1997. Options listed on multiple exchanges have narrower spreads than those listed on a single exchange, but the difference diminishes as option volume increases. Option spreads become wider when a competing exchange delists the option. Options traded under a "Designated Primary Marketmaker" (DPM) have narrower quoted spreads than those traded in a traditional open outcry crowd. Effective spreads are found to be slightly narrower under the DPM than in the crowd, but only since 1992, and only on low-volume options.
\end{abstract}

As WE ENTER THE 21st CENTURY, securities exchanges and regulators around the world face many challenges. Given the current trends toward liberalization and globalization of capital markets, the democratization of information technology, the development of new lower-cost trading mechanisms, and the expansion of derivatives markets in developed and emerging economies, the need to understand the relationship between competition, market structure, and market quality is greater than ever.

The exchange-traded options market in the United States is a natural laboratory for studying how trading mechanisms and the competitive structure of the industry affect market quality. Options trade under both open outcry and specialist mechanisms, in some cases within the same exchange. Moreover, there have been several regulatory regime changes affecting the level of competition between exchanges. Compared to the vast empirical market microstructure literature focusing on stock markets, there has been relatively little published on option market structure. A few authors have addressed the impact of market structure on bid-ask spreads, such as Neal $(1987,1992)$. His research, however, was based on relatively small data sets that predated the important regulatory changes of 1990. Recent developments in the options industry, including antitrust litigation and the creation of a new electronic option exchange, have sparked renewed interest in the issue of interexchange competition on cross-listed securities. In addition to

\footnotetext{
* Terry College of Business, University of Georgia. I would like to thank Mark Rubinstein and the Berkeley Options Data Base for providing office space and computing resources. I would also like to thank Marc Lipson, Shane Corwin, Jeff Netter, Vassil Mihov, and an anonymous referee.
} 
motivating this paper, these developments have inspired complementary, parallel research by Battalio, Hatch, and Jennings (2000), De Fountnouvelle, Fishe, and Harris (2000), and Wang (2000).

This paper examines the effects of competition and market structure on the bid-ask spreads for stock options traded on the Chicago Board Options Exchange (CBOE). It addresses some of the same questions as Neal (1987, 1992), but with a significantly larger and more recent data set. We also make a methodological contribution. Bid-ask spreads on options are positively related to the option's price and negatively related to trading volume. However, because these relationships are nonlinear, regression models are likely to be misspecified. One can attempt to parameterize the nonlinearity in a regression framework, but it can be difficult to know whether such ad hoc specifications are adequate.

In this paper, we circumvent this problem using matched samples. To examine the effect of competition on spreads, we compare quoted and effective bid-ask spreads for multiple-listed and single-listed options, where the two options have a similar price and trading volume, and the two underlying stocks have the same volatility. We find that, at least after 1990, cross-listed options have narrower quoted and effective spreads than single-listed options. However, the difference in effective spreads seems to be less than the difference in quoted spreads, suggesting that there may be more price improvement for single-listed options. Moreover, the difference diminishes as trading volume increases, so that for the most actively traded options in our sample, multiple listing has only a small impact on spreads. As additional evidence that multiple listing matters, we document that spreads become wider when the option is delisted by a competing exchange.

To examine the effect of market structure, we compare options traded under the open outcry structure with those trading under a Designated Primary Marketmaker (DPM). Overall, we find that options traded under a DPM have narrower spreads. However, this result is robust only for quoted spreads, not effective spreads. On average over the entire sample, effective spreads are also narrower for DPM stocks, but we find the opposite result prior to 1991. We also find effective spreads to be wider under a DPM for high-volume options. Consistent with the observations of Grossman and Miller (1988) and Neal (1992), open outcry seems to be a more efficient trading structure than a specialist system for highly liquid securities.

The paper proceeds as follows. Section I contains a short summary of the institutional framework in which options are traded, and of the various regulatory changes that have affected option markets over the years. In Section II, there is a brief review of a few prior empirical papers on this topic. A description of the data used in the analysis is contained in Section III. Section IV describes a matched-sample methodology to control for price, volume, and volatility. Option bid-ask spreads are shown to be sensitive to the trading volume of other options on the same underlying stock. This suggests that we should match not only on price and contract-specific volume, but also on total option volume. In Section V, we use this methodology to test 
whether spreads are related to multiple listing or trading structure. In Section VI, we analyze option spreads before and after delisting by a competing exchange. Also in this section, we attempt to better control for the endogeneity of the listing decision using a probit analysis of listing choices. Section VII summarizes the results and concludes the article.

\section{Institutional Background}

The modern era of exchange-based option trading began in April 1973, with the foundation of the Chicago Board Options Exchange. Subsequently, option trading expanded to the American Stock Exchange (AMEX; January 1975), the Philadelphia Stock Exchange (PHLX; June 1975), the Pacific Exchange (April 1976), the Midwest Stock Exchange (December 1976), the New York Stock Exchange (June 1985), and the International Securities Exchange (May 2000). ${ }^{1}$

\section{A. Competition}

The regulations governing competition between option exchanges in the United States have changed several times over the years. In the 1970s, most options were assigned to trade on a single exchange. However, in 1976 and 1977, a number of stocks were approved for option listing on multiple exchanges. In 1978 and 1979, there was a moratorium on new listings. Then in 1980 , the "allocation plan" went into effect. Under this regime, options were assigned to exchanges according to a lottery system, and no multiple listing was permitted. When OTC stocks were made eligible for option listing in 1985, however, they were eligible for multiple listing, even though the allocation plan remained in effect for options on exchange-listed stocks. In 1990, the allocation plan was abolished, and the Securities and Exchange Commission (SEC) determined that all stocks would be made eligible for multiple listing.

In response to a request from the exchanges, a distinction was made between new option listings and options previously listed on an exchange. Newly listed options were immediately eligible for multiple listing, but eligibility was postponed for previously listed options. These previously listed options gradually became eligible, first in groups of 100 , then in groups of 50 , between 1992 and 1994, until all options were eligible for cross-listing. Despite becoming eligible for multiple listing, however, the exchanges chose not to cross-list previously listed options.

In 1999, the U.S. Justice Department initiated an investigation into trading practices at the option exchanges. In addition, there was an investigation by the SEC, and class actions were filed against the exchanges alleging

\footnotetext{
${ }^{1}$ Options trading was discontinued at the Midwest Stock Exchange in 1980 and at the New York Stock Exchange in 1997.
} 
anticompetitive practices. The failure of the exchanges to cross-list each others' options was presumed to represent collusion between the exchanges to reduce competition. In August 1999, the exchanges began cross-listing options. In September 2000, four exchanges reached a settlement that required them to spend $\$ 77$ million on surveillance and enforcement of trading rules. The class action suit was also settled around the same time.

Another development around this time is that in 1999, the International Securities Exchange, a new, purely electronic option exchange, announced plans to launch early in the year 2000. Thus, even without a Justice Department investigation, it is likely that there would have been increased competition in the option markets.

\section{B. Market Structure}

Another interesting feature of option markets in the United States is that options trade under two different structures. Founded by the Chicago Board of Trade, the CBOE was established with an open-outcry "trading crowd" structure modeled after the trading mechanism used in futures pits. The Pacific Exchange adopted a similar structure. On the other hand, at the AMEX and PHLX, options are traded under a specialist structure resembling that used in stock markets.

In 1985, after several OTC options were multiple-listed on the CBOE and AMEX, most of the trading volume on these contracts went to AMEX. Perhaps because they were concerned about their ability to compete against AMEX for volume on multiple-listed options, the CBOE initiated the "Modified Trading System" market structure in 1987. This allowed the CBOE to list some options under a "Designated Primary Marketmaker" similar to the specialist system used at AMEX. The Pacific Exchange introduced a similar program in 1991, where options are assigned to a "Lead Market Maker."

The responsibilities of the DPM are quite similar to those of a stock specialist. The DPM is a market maker, automatically disseminates quotes, provides liquidity to thin markets by trading on his own account, and represents public limit orders. It should be noted that options traded under a DPM may also be traded by other market makers. For actively traded securities, the DPM mechanism resembles the open outcry structure. The DPM, however, maintains the right to a certain percentage of the public order flow. This means that when there is a DPM, there is less incentive for other market makers to enter when markets are active.

The structural and regulatory changes discussed in this section have given us a rich historical database that allows us to study the impact of competition and market structure on market quality. In particular, we are able to examine the effect of competition on bid-ask spreads by comparing singlelisted options with multiple-listed options trading on the same exchange. In addition, we are able to examine the effect of market structure by comparing options trading under a DPM with others traded in a traditional crowd. 


\section{Literature Review}

\section{A. Multiple Listing}

Shortly after options on OTC stocks were made eligible for multiple listing in 1985, researchers at the SEC began to study the effects of multiple listing. For example, Neal (1987) studied the effects of multiple listing on option market spreads using a sample of 43 options listed on the American Stock Exchange. His sample contained three weeks of transactions-level data (the second week of September 1985, January 1986, and April 1986) for 27 options that were listed only on the AMEX and 16 that were crosslisted on one or more competing exchanges. To study the impact of multiple listing on bid-ask spreads, he examined the coefficient on a dummy variable in a multivariate regression model. Quoted bid-ask spreads were found to be narrower for multiple-listed than for single-listed options. However, Neal found that this difference diminished as trading volume increased. For high-volume contracts, his regression model would actually predict a wider spread for multiple-listed options. Although this point was not emphasized in the paper, it may be important because it suggests that multiple listing does not benefit investors in active markets, where the bulk of trading activity occurs.

Madhavan (1988) reexamined multiple-listing using a simultaneous equation framework designed to account for the fact that spreads and volume are jointly determined. He found no significant effect associated with multiple listing and concluded that Neal's (1987) result was driven by a failure to adequately account for cross-sectional differences in liquidity across contracts.

While these early papers are interesting, they are based on a relatively short sample period, predating the general move to multiple listing in 1990 . Necessarily, the analysis in these papers was confined to a small group of multiple-listed options, primarily on OTC stocks.

More recently, Battalio et al. (2000) used data on 71 multiple-listed option classes from June 19, 2000, to July 21, 2000, to examine the nature of competition between exchanges. Among other results, they document a relationship between quoted spreads and market share, suggesting that the exchanges do, in fact, compete on spreads. However, the dominant exchange continues to attract significant order flow even when their spreads are wider, indicating that other factors come into play. These authors further study the quality of execution in the options market by examining price improvement and the liquidity premium. The focus of their paper is to determine whether or not the option markets collectively provide a competitive and efficient trading environment. They do not compare multiple-listed options with single-listed options, nor do they address the issue of DPM listing. Current research by De Fountnouvelle et al. (2000) and Wang (2000) also addresses multiple listing in option markets. 


\section{B. Market Structure}

Prior to granting permanent approval for the Modified Trading System (trading under the DPM), the SEC mandated that the CBOE conduct internal studies comparing the performance of the DPM and open outcry structures. Apparently, these studies satisfied the SEC that spreads for options traded under a DPM were no wider than those traded in an open outcry system. To the best of our knowledge, these studies were not published, nor has any other study been published comparing options trading under two different structures on the same exchange.

A study by Neal (1992) compares options trading under different structures on different exchanges. Using two weeks of transactions data from 1986, Neal examined bid-ask spreads for 26 AMEX and 15 CBOE options, using a multivariate regression framework similar to that employed in his 1987 paper. For low-volume options, bid-ask spreads were found to be narrower under the specialist structure of the AMEX than under the open outcry structure of the CBOE. For actively traded options, however, Neal's regression model would predict narrower spreads on the CBOE.

\section{Determinants of Option Spreads}

Having examined the results of the papers cited above, we believe the most important control variables affecting option spreads are the option's price and trading volume and the volatility of the underlying stock. Madhavan's (1988) results suggest that an additional liquidity variable besides trading volume might also help explain bid-ask spreads. As a second liquidity control, this paper will use aggregate CBOE trading volume for all option series on the same underlying stock. Details are provided in the following section.

There are a number of other factors reported in the literature as influencing option spreads that we have omitted from our analysis. Berkman (1993) documents a significant negative relationship between limit order activity and the quoted bid-ask spread, demonstrating that even within a competitive market-maker trading environment, limit orders represent a significant additional source of competition. Chan, Chung, and Johnson (1995) and Ap Gwilym, Buckle, and Thomas (1997) identify an intraday pattern in option bid-ask spreads, and Amin and Lee (1997) document that option bidask spreads are wider than normal surrounding earnings announcements.

\section{Data}

The main data source for our analysis is the Berkeley Options Data Base, which is derived from the CBOE Market Data Report, and contains timestamped quotes and trades for all options traded on the CBOE. The analysis is based on more than 11 years of tick-level data on individual stock options, from January 1986 through August 1997. 


\section{A. Market Structure}

The first step in constructing our data set was to identify, for each individual stock option trading on the $\mathrm{CBOE}$, whether it was traded on multiple exchanges or only on the CBOE. This must be determined separately for each date, because options listed on multiple exchanges may become singlelisted when they are delisted from competing exchanges. This was accomplished using data on listings and delistings provided by the CBOE.

The next step was to identify, for each option traded on the CBOE, whether it is traded in a trading crowd or under a DPM. This was accomplished, for most options, using a document provided by the CBOE. A few options, those that had been delisted from the CBOE before 1997, could not be classified using this document. Of these, some were classified using information from news releases available on NEXIS/LEXIS. Others could not be classified and were dropped from consideration.

\section{B. Bid-Ask Spreads}

Daily observations for quoted and effective spreads were calculated as follows. For each option trade, an effective spread is calculated by comparing the trade price to the midpoint of the most recent quoted bid-ask spread. Specifically, suppose that a particular option contract trades $n$ times over the day, transaction $i$ having a price of $P_{i}$ and a volume of $V_{i}$. Let us denote the most recent quoted bid and ask prices prior to transaction $i$ by $A_{i}^{-}$and $B_{i}^{-}$. Transactions recorded before the first quote of the day are discarded. The quoted spread corresponding to transaction $i$ is simply

$$
S_{q i}=A_{i}-B_{i}
$$

and the effective spread for transaction $i$ is given by

$$
S_{e i}=2\left|P_{i}-\frac{A_{i}+B_{i}}{2}\right|
$$

We then convert these to daily observations by calculating dollar-volumeweighted average spreads: ${ }^{2}$

$$
S_{e}=\frac{\sum_{i=1}^{n} V_{i} S_{e i}}{\sum_{i=1}^{n} V_{i}} \quad S_{q}=\frac{\sum_{i=1}^{n} V_{i} S_{q i}}{\sum_{i=1}^{n} V_{i}} .
$$

\footnotetext{
${ }^{2}$ Because the summation is across trades on only one contract and because prices do not change very much over a single day, dollar-volume weights, contract volume weights, and equal weights give almost identical estimates.
} 
This procedure is repeated for calls and puts of all strikes and maturities. Contracts with no trading volume are dropped from our sample.

\section{Price and Volume}

For matching purposes, the analysis requires a daily observation of the option price. Using the same set of bid-ask quotes used to calculate average spreads, we estimate the option price by calculating a weighted average of the quote midpoint with weights equal to the dollar trading volume of the subsequent transaction.

Total volume is calculated for each option contract each day by summing across transactions. In addition, total option volume is calculated for each underlying security, by summing the volume across contracts, including calls and puts of all strikes and maturities, but not including LEAPS.

A problem arises because we have data only from the CBOE. For options trading on multiple exchanges, we will be underestimating the total volume because we do not include volume on the other exchanges. In response to this problem, we will test the robustness of the results when volume is replaced by open interest. Open interest is highly correlated with volume, but open interest is monitored by the Options Clearing Corporation, and therefore the data are aggregated across all exchanges. We obtained daily open interest data beginning in January 1992 from a prominent Chicago-based trading company that is a member of the CBOE and other exchanges. Aggregate open interest for all options on the same underlying stock is calculated by summing across contracts.

\section{Volatility}

To measure volatility, we calculated the implied volatility for each stock, each day, using the same method as is used by the CBOE to calculate the VIX index. First, bid-ask midpoints of eight near-term, near-the-money options are observed, along with contemporaneous underlying stock prices. Next, the implied volatility is calculated for each of the eight options using a binomial model that explicitly accounts for early exercise and discrete dividends. Finally, a weighted average of the eight implied volatilities is calculated, with the weights chosen so that the resulting estimate represents the implied volatility of an at-the-money option with 22 trading days to maturity.

\section{Methodology}

\section{A. Motivation for a Matched-sample Methodology}

Our goal is to analyze the effect of market structure on bid-ask spreads, while correcting for the effects of other variables, primarily the price level and trading volume, that may influence spreads. In such situations, multivariate regression analysis seems a natural choice. However, for various reasons, we believe a linear regression model would be misspecified. 


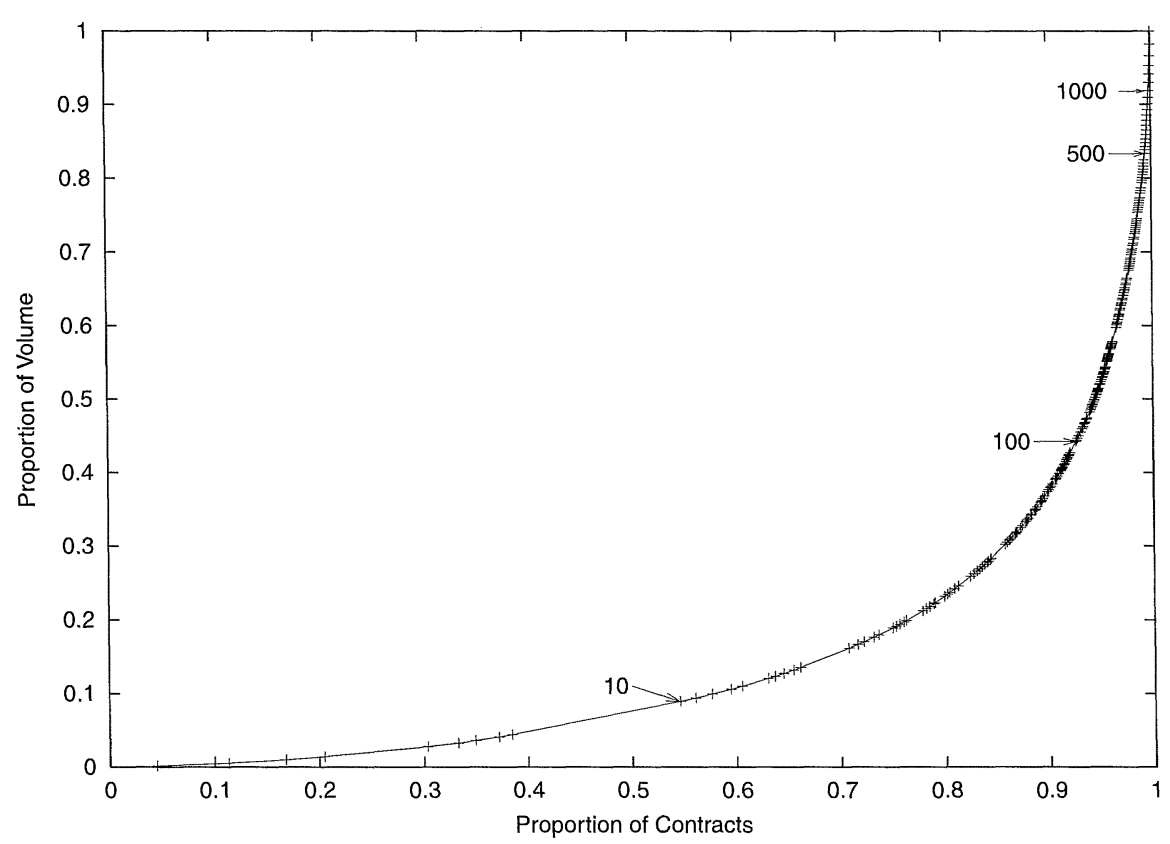

Figure 1. The distribution of trading volume across option contracts, August 29, 1997. Based on all stock option contracts traded on the Chicago Board Option Exchange, excluding contracts with zero volume.

For one, the relationship between bid-ask spreads and option prices appears to be nonlinear. A simple examination of the data reveals, as one would expect, that dollar bid-ask spreads tend to increase with the price of the option, but at a decreasing rate. Percentage spreads tend to decrease (at a decreasing rate) with the price of the option. In addition, the relationship between option price and spreads is influenced by institutional features of the market. There is a regulatory limit on the maximum permissible quoted spread under normal market conditions, but this limit changes as a function of the option price, with regime changes at 1 dollar, 2 dollars, 5 dollars, 10 dollars, and 20 dollars. Also, the tick size changes at 3 dollars, and for very lowpriced options, the minimum tick size imposes a lower bound on the spread. In summary, for both fundamental and institutional reasons, neither dollar nor percentage bid-ask spreads are linear with respect to the option price.

The relationship between spreads and volume is also nonlinear. The bidask spread appears to be a decreasing, convex function of volume. Moreover, it should be noted that the vast majority of option contracts have very low volume, and a small minority have very high volume. This is illustrated in Figure 1, which shows the distribution of trading volume across option contracts. Of all stock options that traded on August 29, 1997, 54 percent traded 10 contracts or less, and 92 percent traded 100 or less. Many more contracts did not trade at all, but these are not included in our sample. 
If a linear regression model were to be estimated across contracts, the low-volume contracts would have a dominant influence over the parameter estimate for the volume coefficient. Since the relationship between spreads and volume is decreasing and convex, the regression is likely to underestimate the bid-ask spread for high volume options, or even produce a negative estimate. For example, in both papers by Neal $(1987,1992)$, the regression coefficients indicate diminishing effects as trading volume increases. Because the models are linear, the predicted effects not only diminish, but change sign for high-volume options. Does the sign really change, or is this just a result of linear extrapolation?

One possibility is to use weighted least squares regression with volume weights. In this case, the model will fit the high-volume options better, but would have trouble fitting the low-volume options. Neal (1992) and others have attempted to deal with this problem by subjecting trading volume to various manipulations, such as using natural logarithms. While such transformations may fit the data better, they are necessarily ad hoc and likely to be misspecified.

For these reasons, this paper employs a matched-sample methodology instead of a regression framework. Pairs of options, matched according to a set of control variables, are selected to isolate a characteristic of interest, such as whether the option is multiple listed, or whether it trades under a DPM. This makes it possible to test whether that particular characteristic influences spreads without having to make any assumptions about the functional relationship between spreads and the control variables.

\section{B. Selecting the Control Variables}

In selecting the set of control variables, there is a trade-off. On one hand, one would like to hold constant all the important factors affecting bid-ask spreads, so that any systematic variation can be attributed to the one characteristic that differs. On the other hand, if one attempts to match on too many variables, the sample is likely to be small. To achieve relatively close matching and still obtain a suitable sample size, the sample must be drawn from a large population. Accordingly, the sample used in this paper is drawn from over 11 years of tick data. Compared to prior research in this area, this is a relatively large data set. Recall that Neal (1987) analyzed three weeks of data.

In selecting matched pairs of options, it was required that the two observations occur on the same day. It is possible that options spreads may be influenced by the level of market volatility, macroeconomic variables, or any other variable that changes from day to day or year to year. Over the 11 years of the sample, markets have matured, regulations have changed, and trading technology has evolved. Additionally, there may be calendar effects such as Monday, triple witching hour, or January effects. Matching by date controls for all omitted variables that are related to the calendar or to the economic environment. 
Based on the prior literature and conventional wisdom, we believe a priori that the option's price is one of the most important determinants of the bid-ask spread. Naturally, quoted bid-ask spreads are wider for higher priced options. As a percentage of the option price, spreads are significantly lower for high priced options. So, regardless of whether absolute or relative spreads are used, it is important to control for the price level. However, options should not be matched exactly by quote midpoints, for this would severely bias the sample toward pairs of options with identical quoted spreads. Instead, we require that the two option prices be within 50 cents of each other.

In addition to matching by price, we also match options by trading volume. Before proceeding, we wished to verify that trading volume affects spreads in our sample, after controlling for price. A sample was constructed consisting of pairs of options, observed on the same day, with roughly the same price, and written on the same underlying stock, where one option had high trading volume and one had low trading volume. For example, an actively traded at-the money short-term option might be matched to an infrequently traded out-of-the-money long-term option on the same stock. Or an actively traded at-the-money call could be matched with a less actively traded at-the-money put.

To define "high" and "low" volume, all contracts traded in the day were sorted by volume, then divided into five groups, with each group accounting for one fifth of the total contract volume. Options in the lowest volume group were then paired with options in the highest volume group. Quoted and effective spreads were then compared for high volume and low volume options. Mean and median differences, across a sample of 24,361 matched pairs of options, are reported in Table I. As expected, in the entire sample and in each yearly subperiod, spreads are significantly narrower for high-volume contracts. Although $t$-statistics and Wilcoxon signed rank test statistics are not reported in the table, these tests were statistically significant at the one percent level for the entire sample and each subperiod.

Sometimes, an option contract can be liquid even if it has low trading volume. For example, this may occur if other options on the same stock are actively traded. It is easier for a market maker to hedge a low-volume option if there are actively traded options at other strikes and maturities. In addition, active markets for other options on the same underlying stock increases the likelihood that a market maker will be looking for a hedge.

To test whether this is an important determinant of option bid-ask spreads, another matched sample was constructed, as follows. For each underlying stock each day, total volume was aggregated across calls and puts of all maturities and strikes. Underlying stocks were classified as having "high" or "low" aggregate volume using the same procedure as for contract volume. Then, matched pairs of options were selected, with the two options observed on the same date, with roughly the same price and contract volume, but on different underlying stocks, one with high and one with low aggregate option volume. This procedure resulted in 96,836 matched pairs of options. Mean and median differences in quoted and effective spreads are reported in 


\section{Table I \\ Differences in Spreads-High-volume Versus Low-volume Option Contracts}

This table compares spreads on options in the highest volume group with those in the lowest, controlling for date, underlying stock, and option price. Mean and median differences in quoted and effective bid-ask spreads are reported from a sample of 24,361 pairs of options. A negative number indicates that high-volume options have narrower spreads than low-volume options. For all subperiods, both the $t$-test for means and the Wilcoxon signed rank test indicate a statistically significant difference between the two samples at the one percent level.

\begin{tabular}{ccccccc}
\hline & & \multicolumn{2}{c}{ Quoted Spreads } & & \multicolumn{2}{c}{ Effective Spreads } \\
Year & $N$ & Mean Diff. & Median Diff. & & Mean Diff. & Median Diff. \\
\hline 1986 & 1,673 & -0.09962 & -0.05769 & & -0.06376 & -0.03055 \\
1987 & 2,133 & -0.10048 & -0.07111 & & -0.07202 & -0.04207 \\
1988 & 1,308 & -0.07615 & -0.05432 & & -0.04576 & -0.01524 \\
1989 & 1,586 & -0.07423 & -0.05385 & & -0.04504 & -0.01876 \\
1990 & 1,636 & -0.04582 & -0.03581 & & -0.02794 & -0.01010 \\
1991 & 1,419 & -0.04541 & -0.03465 & & -0.02853 & -0.00962 \\
1992 & 1,928 & -0.02951 & -0.02038 & & -0.02767 & -0.01233 \\
1993 & 2,039 & -0.03253 & -0.01979 & & -0.03199 & -0.01345 \\
1994 & 2,140 & -0.02239 & -0.00971 & & -0.03292 & -0.01826 \\
1995 & 2,761 & -0.03361 & -0.02440 & & -0.04016 & -0.02608 \\
1996 & 3,409 & -0.03042 & -0.01809 & & -0.05024 & -0.03825 \\
1997 & 2,329 & -0.03990 & -0.02583 & & -0.06246 & -0.05467 \\
$1986-1997$ & 24,361 & -0.04919 & -0.03017 & & -0.04492 & -0.02469 \\
\hline
\end{tabular}

Table II. These results verify that after accounting for contract-specific volume, spreads are narrower for options with high aggregate option volume. As before, $t$-statistics and Wilcoxon signed rank test statistics are significant at the one percent level for each yearly subperiod. ${ }^{3}$ The differences tend to be as large or even larger than those reported in the previous table, suggesting that aggregate option volume is an important factor influencing spreads.

Now we have matched by date, option price, contract volume, and aggregate option volume. Based on the prior literature, we believe the next most important determinant of spreads to be the volatility of the underlying asset. To test whether quoted or effective spreads are affected by volatility, another matched sample was created. Underlying stocks were segregated into quintiles on the basis of implied volatility. Stocks in the highest quintile were classified as "high volatility" and those in the lowest were classified as "low volatility." Options on high volatility stocks were then paired with those on low volatility stocks, controlling for date, price, contract volume, and aggregate option volume. Table III reports mean and median differences in quoted and effective spreads.

${ }^{3}$ Note that Wilcoxon test statistics can indicate a significant difference in the two samples even if the median difference is zero. 


\section{Table II \\ Differences in Spreads-High Versus \\ Low Aggregate Option Volume}

This table compares spreads on options in the highest aggregate volume group with those in the lowest, controlling for date, option price, and the option's own contract volume. Aggregate volume is measured as total CBOE volume for all option series on the same underlying security. Mean and median differences in quoted and effective bid-ask spreads are reported for a sample of 96,836 pairs of options. A negative number indicates that options with higher aggregate volume have narrower spreads. For all subperiods, both the $t$-test for means and the signed rank test indicate a statistically significant difference between the two samples at the one percent level.

\begin{tabular}{ccccccr}
\hline & & \multicolumn{2}{c}{ Quoted Spreads } & & \multicolumn{2}{c}{ Effective Spreads } \\
Year & $N$ & Mean Diff. & Median Diff. & & Mean Diff. & Median Diff. \\
\hline 1986 & 7,260 & -0.13567 & -0.12500 & & -0.04536 & -0.02017 \\
1987 & 9,288 & -0.09882 & -0.06484 & & -0.02153 & 0.00000 \\
1988 & 5,193 & -0.12486 & -0.11614 & & -0.04489 & -0.01650 \\
1989 & 5,905 & -0.09637 & -0.07522 & & -0.03956 & -0.01660 \\
1990 & 5,961 & -0.07248 & -0.05151 & & -0.04164 & -0.02086 \\
1991 & 5,682 & -0.09880 & -0.08802 & & -0.07233 & -0.05388 \\
1992 & 6,276 & -0.07798 & -0.06250 & & -0.06131 & -0.04271 \\
1993 & 6,782 & -0.06223 & -0.06250 & & -0.06297 & -0.05227 \\
1994 & 7,527 & -0.09321 & -0.07654 & & -0.09041 & -0.06250 \\
1995 & 10,524 & -0.05459 & -0.04405 & & -0.06135 & -0.05420 \\
1996 & 15,394 & -0.04141 & -0.02227 & & -0.05969 & -0.05608 \\
1997 & 11,044 & -0.01977 & 0.00000 & & -0.04753 & -0.03595 \\
$1986-1997$ & 96,836 & -0.07391 & -0.0625 & & -0.05408 & -0.03846 \\
\hline
\end{tabular}

After accounting for other factors, volatility appears to have a relatively minor impact on bid-ask spreads. In the entire sample, we find that mean quoted spreads are slightly narrower for options on low volatility stocks but the median difference is zero, and there is no significant difference in effective spreads. Examining annual subperiods, we find the median difference to be zero most years for quoted spreads and zero every year for effective spreads. High volatility is associated with wider spreads in the earlier years of our sample, but the mean differences are often statistically indistinguishable from zero. In the later years of our sample, options on high volatility stocks tend to have slightly narrower spreads than those on low volatility stocks.

Given these results, it is not clear whether or not it is appropriate to control for underlying volatility in our analysis of market structure. On one hand, there appears to be no strong, robust association between volatility and spreads, and controlling for one more variable will significantly reduce the final sample size. On the other hand, volatility does have a statistically significant impact on both quoted and effective spreads in many subperiods, even for effective spreads. Accordingly, we will report results both with and without a volatility control. To control for volatility, we will match pairs of options with implied volatilities differing by less than 0.02 . 


\section{Table III}

\section{Differences in Spreads-High Versus Low Volatility}

This table compares spreads on options in the highest volatility quintile with those in the lowest, controlling for date, option price, the option's own contract volume, and aggregate option volume. Volatility is measured as the implied volatility of short-term at-the-money options on the underlying stock. Mean and median differences in quoted and effective bid-ask spreads are reported for a sample of 106,689 pairs of options. A positive number indicates that options on stocks with higher volatility have wider spreads. An asterisk indicates a $t$-statistic that is significant at the one percent level.

\begin{tabular}{|c|c|c|c|c|c|}
\hline \multirow[b]{2}{*}{ Year } & \multirow[b]{2}{*}{$N$} & \multicolumn{2}{|c|}{ Quoted Spreads } & \multicolumn{2}{|c|}{ Effective Spreads } \\
\hline & & Mean Diff. & Median Diff. & Mean Diff. & Median Diff. \\
\hline 1986 & 7,568 & $0.01124^{*}$ & 0.00000 & 0.00400 & 0.00000 \\
\hline 1987 & 9,011 & 0.00171 & 0.00000 & 0.00328 & 0.00000 \\
\hline 1988 & 7,048 & $-0.00803^{*}$ & 0.00000 & 0.00159 & 0.00000 \\
\hline 1989 & 6,915 & $0.01001^{*}$ & 0.00000 & $0.01155^{*}$ & 0.00000 \\
\hline 1990 & 8,015 & $0.00415^{*}$ & 0.00000 & $0.00548 *$ & 0.00000 \\
\hline 1991 & 7,907 & $-0.02228 *$ & 0.00000 & $0.00571^{*}$ & 0.00000 \\
\hline 1992 & 10,251 & $-0.03882^{*}$ & -0.02225 & -0.00023 & 0.00000 \\
\hline 1993 & 14,250 & $-0.03129 *$ & -0.02093 & -0.00054 & 0.00000 \\
\hline 1994 & 15,972 & $-0.02945^{*}$ & -0.01477 & $-0.00433^{*}$ & 0.00000 \\
\hline 1995 & 19,752 & $-0.02777^{*}$ & -0.00759 & $-0.00376^{*}$ & 0.00000 \\
\hline 1996 & 19,238 & $-0.02050^{*}$ & 0.00000 & $-0.00591^{*}$ & 0.00000 \\
\hline 1997 & 12,822 & $-0.02429 *$ & 0.00000 & $-0.01307^{*}$ & 0.00000 \\
\hline $1986-1997$ & 106,689 & $-0.01774^{*}$ & 0.00000 & 0.00081 & 0.00000 \\
\hline
\end{tabular}

Each step in the matching process significantly reduces the potential sample size for our analysis of market structure. After matching by date, option price, contract volume, total option volume, and implied volatility, we still obtain a large enough sample to make reliable inferences. However, we feel that reducing the sample any further by matching on additional characteristics would result in a sample too small to inspire confidence.

\section{Competition and Market Structure}

The main goal of this study is to test whether competition or market structure affects spreads. First, we will examine whether quoted and effective spreads are related to multiple listing. Then we will investigate whether spreads on options traded under a DPM market structure differ from those trading in a traditional pit.

\section{A. Multiple Listing}

To study the impact of multiple listing, single-listed options were paired with multiple-listed options. No distinction was made between options listed on two exchanges and options listed on more than two exchanges. In our first specification, options are matched according to date, price, contract- 
Table IV

\section{Differences in Spreads-Single Versus Multiple Listings}

This table compares spreads on single-listed options with those on cross-listed options, controlling for date, option price, the option's own contract volume, and aggregate option volume. Mean differences, median differences, and percentage of nonzero differences positive are reported for both quoted and effective bid-ask spreads. Tests were based on a sample of 690,222 pairs of options. A negative number indicates that multiple-listed options have narrower spreads. An asterisk following the mean difference indicates a $t$-statistic that is significant at the one percent level. An asterisk following the percentage positive statistic indicates a Wilcoxon signed rank test statistic significant at the one percent level, with a plus sign indicating wider spreads for multiple-listed options.

\begin{tabular}{|c|c|c|c|c|c|c|c|}
\hline \multirow[b]{2}{*}{ Year } & \multirow[b]{2}{*}{$N$} & \multicolumn{3}{|c|}{ Quoted } & \multicolumn{3}{|c|}{ Effective } \\
\hline & & $\begin{array}{l}\text { Mean } \\
\text { Diff. }\end{array}$ & $\begin{array}{l}\text { Median } \\
\text { Diff. }\end{array}$ & $\begin{array}{c}\% \\
\text { Positive }\end{array}$ & $\begin{array}{l}\text { Mean } \\
\text { Diff. }\end{array}$ & $\begin{array}{l}\text { Median } \\
\text { Diff. }\end{array}$ & $\begin{array}{c}\% \\
\text { Positive }\end{array}$ \\
\hline 1986 & 15,064 & $0.00500 *+$ & 0.00000 & $53.55^{*}+$ & 0.00155 & 0.00000 & 51.16 \\
\hline 1987 & 17,003 & $-0.01102^{*}$ & 0.00000 & $47.41^{*}$ & $-0.00485^{*}$ & 0.00000 & $47.89 *$ \\
\hline 1988 & 14,601 & $-0.01561^{*}$ & 0.00000 & $45.13^{*}$ & -0.00070 & 0.00000 & 48.80 \\
\hline 1989 & 15,970 & $0.00780 *+$ & 0.00000 & $51.53^{*}+$ & 0.00321 & 0.00000 & 50.57 \\
\hline 1990 & 17,827 & $-0.01903^{*}$ & 0.00000 & $40.68^{*}$ & $-0.01245^{*}$ & 0.00000 & $47.24^{*}$ \\
\hline 1991 & 24,829 & $-0.05065^{*}$ & -0.03440 & $28.11^{*}$ & $-0.02820^{*}$ & -0.00825 & $42.54^{*}$ \\
\hline 1992 & 44,815 & $-0.07056^{*}$ & -0.06250 & $19.95^{*}$ & $-0.03285^{*}$ & -0.01433 & $41.31 *$ \\
\hline 1993 & 64,313 & $-0.06066^{*}$ & -0.06250 & $21.79^{*}$ & $-0.03494^{*}$ & -0.02056 & $40.20 *$ \\
\hline 1994 & 80,731 & $-0.05614^{*}$ & -0.06250 & $23.98^{*}$ & $-0.04244^{*}$ & -0.03266 & $37.34 *$ \\
\hline 1995 & 147,178 & $-0.03958^{*}$ & -0.03648 & $28.98^{*}$ & $-0.03070^{*}$ & -0.01865 & $40.26^{*}$ \\
\hline 1996 & 147,729 & $-0.03277^{*}$ & -0.00736 & $31.90^{*}$ & $-0.03242^{*}$ & -0.01860 & $39.47^{*}$ \\
\hline 1997 & 100,162 & $-0.03549^{*}$ & -0.01177 & $30.69^{*}$ & $-0.03528^{*}$ & -0.02341 & $38.27^{*}$ \\
\hline $1986-1997$ & 690,222 & $-0.04003^{*}$ & -0.02785 & $30.03^{*}$ & $-0.03032^{*}$ & -0.01563 & $40.68^{*}$ \\
\hline
\end{tabular}

specific volume, and aggregate option volume, but not volatility. Mean and median differences in spreads are reported in Table IV for the entire sample and yearly subperiods. Prior to late 1990, the multiple-listed options in the sample are either among those few stocks that were cross-listed in the 1970s, or they are options on OTC stocks. In this respect, the early sample resembles that used by Neal (1987). The results in Table IV indicate that prior to 1992 , there is little evidence for any significant, robust relationship between spreads and multiple listing. Each year from 1986 to 1990, the median difference in both the quoted and effective spreads is zero. The mean differences are positive some years and negative other years. In 1986, 1988, and 1989 , the mean difference in effective spread is statistically indistinguishable from zero.

Things appear to have changed at the time that multiple listing was permitted for all stocks. Every year beginning in 1990, the mean differences for both quoted and effective spreads are negative, indicating narrower spreads for multiple-listed stocks. This result is reinforced by the Wilcoxon signed rank test statistics, which are significant for both measures of the spread each year beginning in 1990 . 
Table V

\section{Differences in Spreads-Single Versus Multiple Listings}

This table compares spreads on single-listed options with those on cross-listed options, controlling for date, option price, the option's own contract volume, aggregate option volume, and implied volatility. Mean and median differences are reported for both quoted and effective bidask spreads. Tests were based on a sample of 17,562 pairs of options. A negative number indicates that multiple-listed options have narrower spreads. An asterisk indicates a $t$-statistic that is significant at the one percent level.

\begin{tabular}{|c|c|c|c|c|c|}
\hline \multirow[b]{2}{*}{ Year } & \multirow[b]{2}{*}{$N$} & \multicolumn{2}{|c|}{ Quoted } & \multicolumn{2}{|c|}{ Effective } \\
\hline & & Mean Diff. & Median Diff. & Mean Diff. & Median Diff. \\
\hline 1986 & 989 & -0.01332 & 0.00000 & $-0.02100^{*}$ & -0.00016 \\
\hline 1987 & 1,058 & $-0.02942^{*}$ & 0.00000 & $-0.02200^{*}$ & -0.01208 \\
\hline 1988 & 663 & $-0.02695^{*}$ & 0.00000 & -0.01554 & -0.00171 \\
\hline 1989 & 1,006 & 0.00404 & 0.00000 & -0.00820 & 0.00000 \\
\hline 1990 & 781 & -0.00301 & 0.00000 & 0.00405 & 0.00000 \\
\hline 1991 & 875 & $-0.02004^{*}$ & 0.00000 & $-0.02102^{*}$ & 0.00000 \\
\hline 1992 & 1,091 & $-0.05904^{*}$ & -0.04268 & $-0.02871^{*}$ & -0.00467 \\
\hline 1993 & 1,708 & $-0.06602^{*}$ & -0.06250 & $-0.03998^{*}$ & -0.02346 \\
\hline 1994 & 2,119 & $-0.06015^{*}$ & -0.06250 & $-0.04232^{*}$ & -0.02526 \\
\hline 1995 & 3,690 & $-0.03337^{*}$ & -0.02099 & $-0.03693^{*}$ & -0.01982 \\
\hline 1996 & 1,892 & $-0.04568^{*}$ & -0.03502 & $-0.05215^{*}$ & -0.04632 \\
\hline 1997 & 1,690 & $-0.04762^{*}$ & -0.04493 & $-0.04344^{*}$ & -0.03634 \\
\hline $1986-97$ & 17,562 & $-0.38300^{*}$ & -0.01028 & $-0.03277^{*}$ & -0.01515 \\
\hline
\end{tabular}

Across the entire sample, the quoted spread on a multiple-listed option is, on average, four cents narrower than on otherwise similar single-listed options (for the median pair, about 0.0278 narrower). The effective spread is only three cents narrower on average (median 0.0156). The fact that spreads are narrower on multiple-listed stocks suggests that competition across exchanges may decrease bid-ask spreads. However, the fact that the difference is smaller for effective spreads than for quoted spreads suggests that there may be more price improvement for single-listed options than for multiplelisted options.

Table V reports results after controlling for implied volatility. Here, the samples are considerably smaller, but the sign and magnitude of the multiplelisting effects are quite similar to those reported in Table IV. The differences are minor: The significantly positive coefficients for quoted spreads in 1986 and 1989 have disappeared, and the coefficients in 1990 are no longer significant.

We were concerned that our results may be biased because we are underestimating trading volume on multiple-listed contracts by using only CBOE data. We repeated our analysis for the period 1992-1997 matching on open interest instead of trading volume. The open interest data includes all exchanges and is not subject to this measurement bias. For the years covered by our open interest data, the results were virtually identical to those reported in Table IV. For the sake of brevity, the results have not been reported here. 
Note that all options in our sample have been weighted equally. As illustrated in Figure 1, there is an unequal distribution of trading volume across options. If one were concerned about the economic impact of multiple listing, one might want to focus primarily on the high-volume options, where most of the trading volume occurs. To investigate how the differences between single- and multiple-listed option spreads relate to trading volume, we divided the sample into 19 subsamples, the first 9 corresponding to the bottom nine volume deciles, and the remaining 10 corresponding to the top ten percentiles. Figure $2 \mathrm{a}$ plots effective and quoted spreads for multiple-listed and single-listed options, as a function of mean trading volume, and Figure $2 \mathrm{~b}$ plots the difference between spreads on single- and multiple-listed stocks, as a function of volume.

Based on these graphs, let us make three observations. First, Figure 2a verifies that spreads are a nonlinear function of volume, justifying our choice to use a matched sample methodology instead of multivariate regression. Second, the result that multiple-listed options have narrower spreads than single-listed options is robust-the same result is observed for both quoted and effective spreads in each of the 19 subsets. Third, the difference between spreads on multiple- and single-listed options is considerably smaller for high-volume options than for low-volume ones. For the most liquid options in our sample, the difference in effective spreads is less than 0.005 . However, the vast majority of options in our sample have low trading volume, and the difference in spreads is much higher for these options. This suggests that the means and medians reported in Table IV overstate the impact of multiple listing for the active options where most of the trading occurs.

Figure 3 plots quoted and effective spreads for single-listed and multiplelisted options as a function of the option price. The graph was created by sorting the sample into 50-cent bins, based on the average price of the two options in the pair, then calculating mean spreads within each bin. More than half of the 690,222 observations fall in the first four price bins. As the price increases, the subsamples get smaller, and the sampling error increases. All bins above $\$ 20$ contained fewer than 100 pairs of options and so the graph was truncated at this point. This graph confirms the robustness of the result that multiplelisted options tend to have narrower quoted and effective spreads. It also verifies that spreads are a nonlinear function of the price, which suggests that the linear regression models often used to model bid-ask spreads are misspecified.

Figure 4 plots quoted and effective spreads for single-listed and crosslisted options as a function of implied volatility. Multiple-listed options have narrower quoted and effective spreads at all volatility levels.

\section{B. Market Structure}

To examine the effect of market structure, options traded under a DPM were paired with options traded in a traditional trading crowd. As in the previous section, options were first matched by date, price, contract-specific volume, and aggregate option volume. Quoted and effective spreads were then compared across groups. 
PANEL A

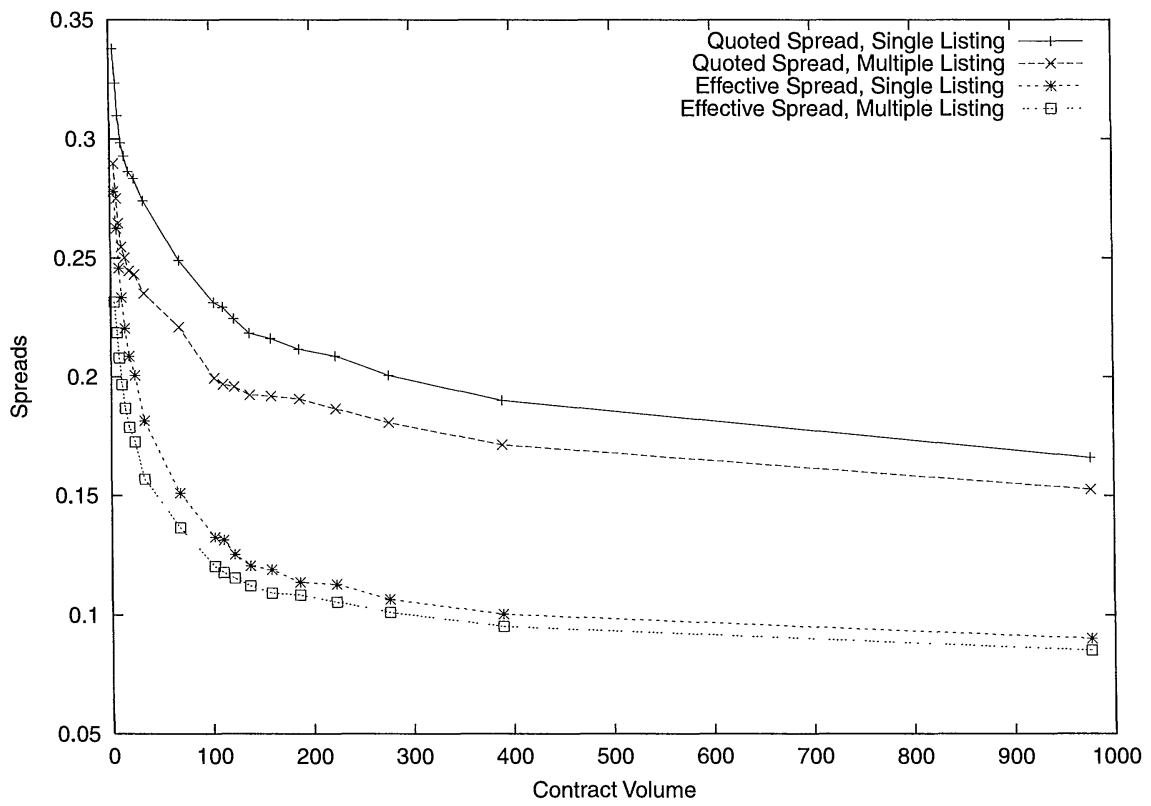

PANEL B

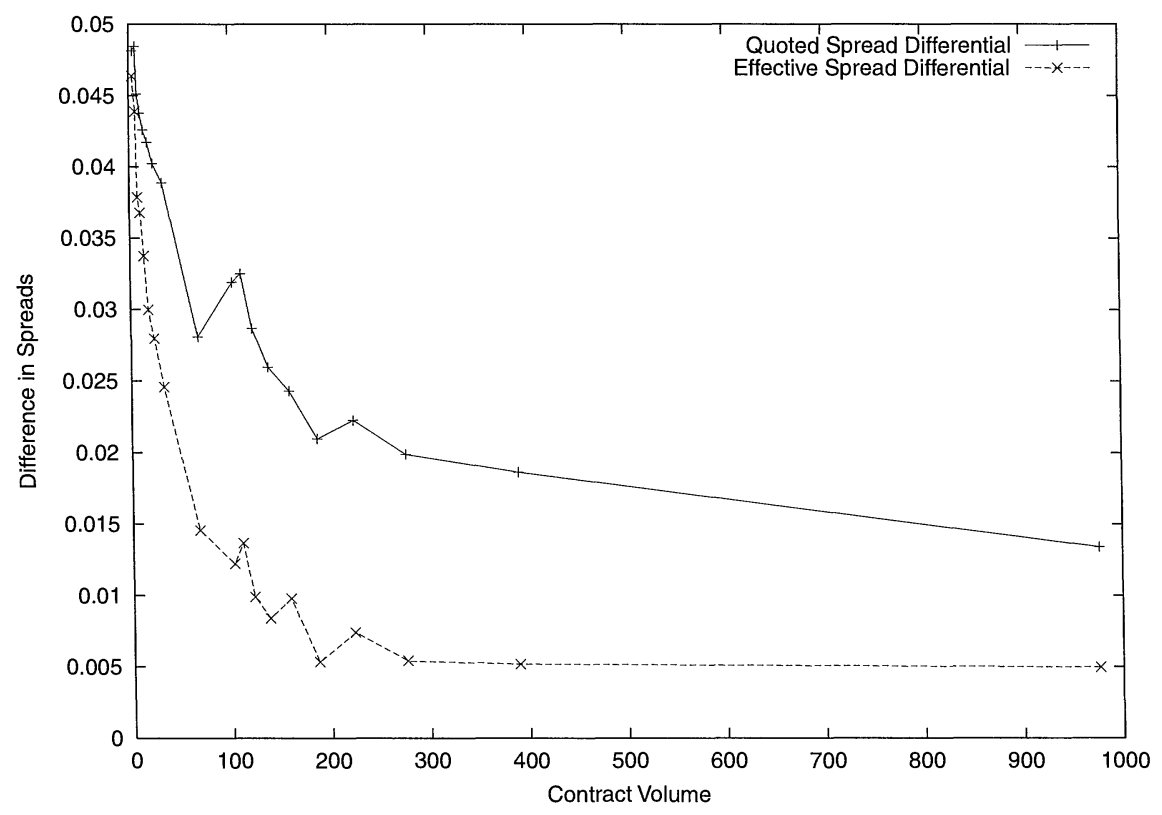

Figure 2. Quoted and effective spreads for single-listed versus multiple-listed options, as a function of trading volume. The graph is based on a sample of 690,222 pairs of options, matched according to date, price, contract-specific volume, and total option volume, with one option single listed and one multiple listed. The first 9 points correspond to the bottom 9 volume deciles. The next 10 points correspond to the highest 10 volume percentiles. 


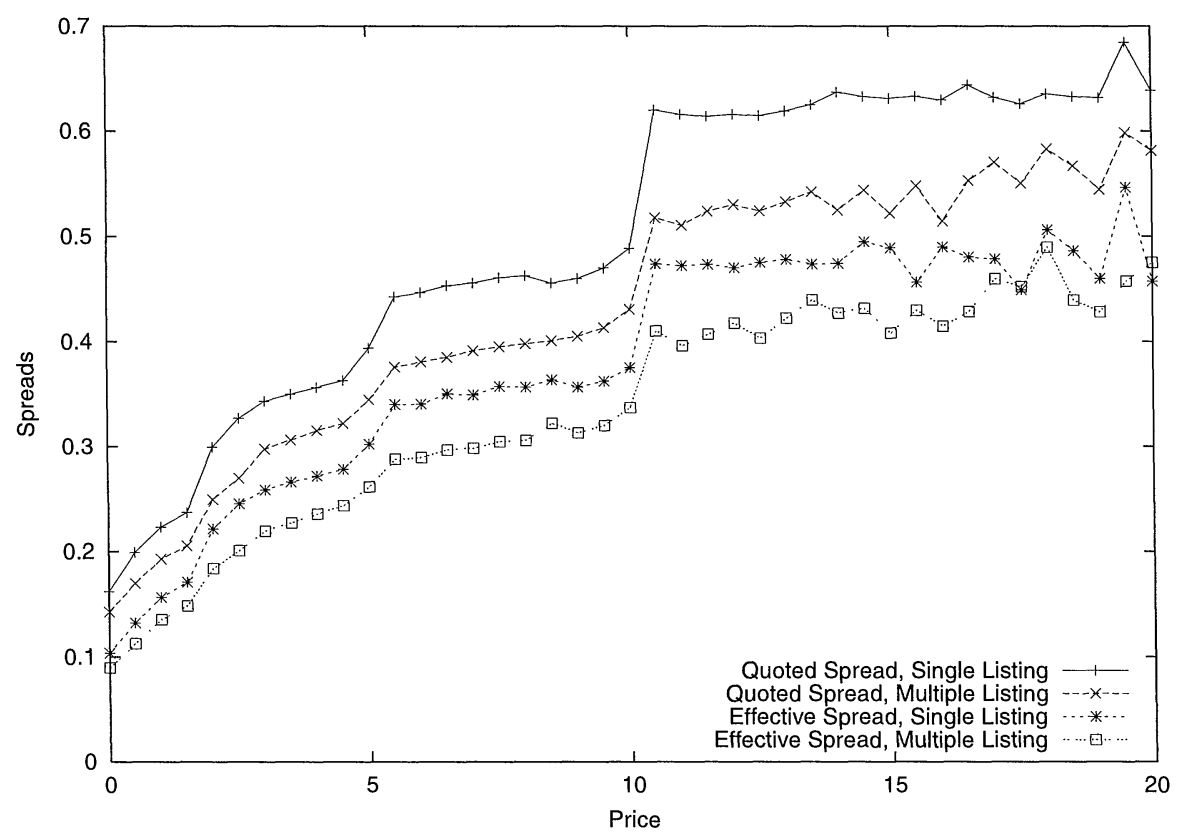

Figure 3. Quoted and effective spreads for single-listed versus multiple-listed options, as a function of option price. The graph is based on a sample of 690,222 pairs of options, matched according to date, price, contract-specific volume, and total option volume, with one option single listed and one multiple listed.

The results reported in Table VI indicate that across the entire sample, spreads tend to be narrower for options trading under a DPM than those trading in a crowd. Subsample analysis reveals that this result is fairly robust for quoted spreads, appearing each year since 1988. Effective spreads are sufficiently close under the two market structures that the median difference is zero each year in our sample. Examining mean differences and the Wilcoxon signed rank test, we find that each year until 1991, effective spreads were wider for the DPM than for the trading crowd, despite having narrower quoted spreads. Each year since 1992, mean quoted and effective spreads have been narrower for DPM options. We also find that each year, the difference in spreads across the two groups is larger for quoted spreads than for effective spreads. This suggests that even though quoted spreads are narrower under a DPM, there appears to be a higher likelihood of price improvement in a trading crowd.

Table VII reports the results after controlling for implied volatility. Compared with those in Table VI, these results indicate a slightly larger difference in both quoted and effective spreads across the two groups. Also, we no longer see the result that effective spreads were wider under the DPM prior to 1991. Now, market structure appears to have no significant impact on effective spreads during that period. 


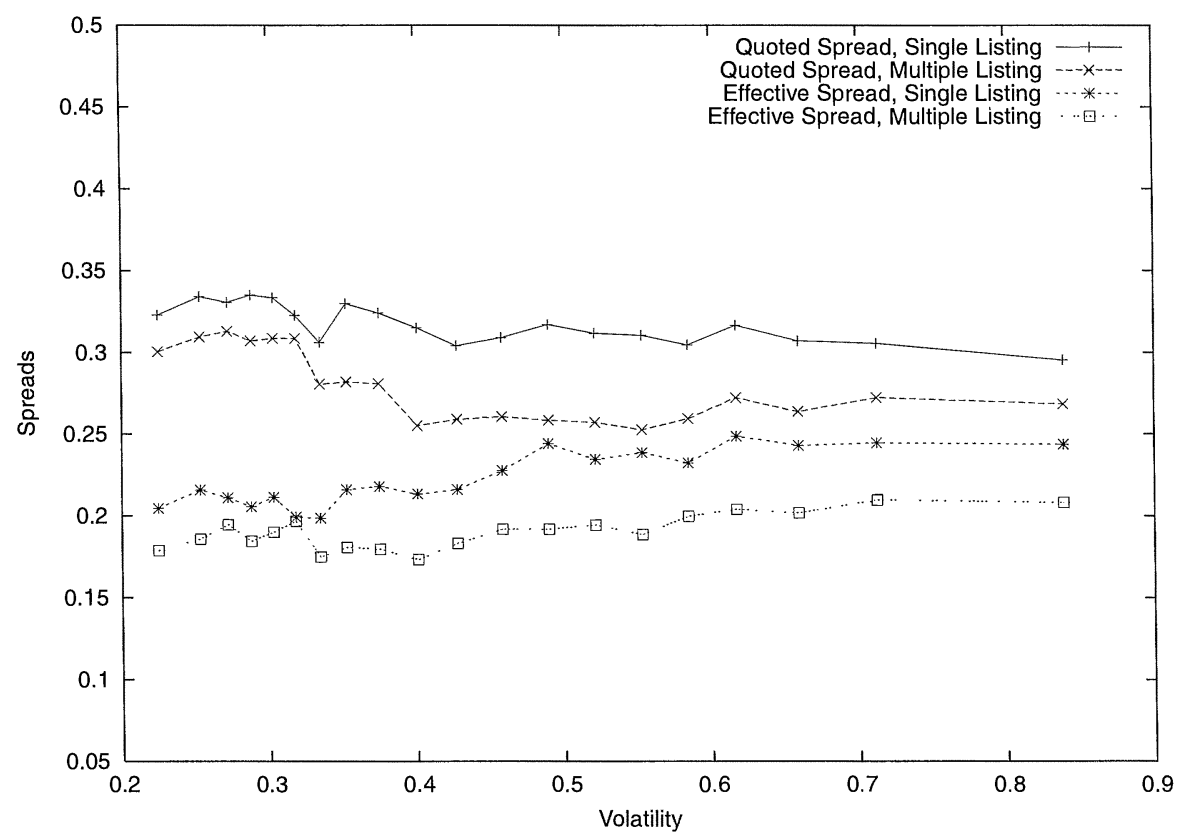

Figure 4. Quoted and effective spreads for single-listed versus multiple-listed options, as a function of implied volatility. The graph is based on a sample of 17,562 pairs of options, matched according to date, price, contract-specific volume, total option volume, and implied volatility, with one option single listed and one multiple listed.

Grossman and Miller (1988) observed that the specialist plays an important role in providing immediacy for low-volume securities, but the open outcry mechanism is more efficient for active markets with a high demand for immediacy. To investigate the relationship between trading volume and liquidity under the two market structures, we examine volume-based subsamples. The graph shown in Figure 5 is consistent with the observations of Grossman and Miller and with the results of Neal (1992). Effective spreads appear to be narrower under a DPM, as compared to a trading crowd, for low-volume options, but the opposite appears to be true for high-volume options. These differences seem to be relatively small, however.

Figure 6 shows quoted and effective spreads for DPM and trading crowd options, as a function of the option price. Likewise, Figure 7 depicts quoted and effective spreads as a function of implied volatility. The result that options traded under a DPM have narrower bid-ask spreads appears to hold for options at all price levels and for all volatilities.

\section{The Impact of Endogeneity}

Whether or not a new option is multiple listed is determined by the exchanges. Their choices may be influenced by characteristics that also affect bid-ask spreads, but that have been omitted from our analysis. Thus, it is 
Table VI

\section{Differences in Spreads-Designated Primary Marketmaker Versus Trading Crowd}

This table compares spreads on options traded under a DPM with those traded in a traditional trading crowd, controlling for date, option price, the option's own contract volume, and aggregate option volume. Mean differences, median differences, and percentage of nonzero differences positive are reported, for both quoted and effective bid-ask spreads. Tests were based on a sample of 729,645 pairs of options. A negative number indicates that options traded under a DPM have narrower spreads. An asterisk following the mean difference indicates a $t$-statistic that is significant at the one percent level. An asterisk following the percentage positive statistic indicates a Wilcoxon signed rank test statistic significant at the one percent level, with a plus sign indicating wider spreads for multiple-listed options.

\begin{tabular}{|c|c|c|c|c|c|c|c|}
\hline \multirow[b]{2}{*}{ Year } & \multirow[b]{2}{*}{$N$} & \multicolumn{3}{|c|}{ Quoted } & \multicolumn{3}{|c|}{ Effective } \\
\hline & & $\begin{array}{l}\text { Mean } \\
\text { Diff. }\end{array}$ & $\begin{array}{l}\text { Median } \\
\text { Diff. }\end{array}$ & $\begin{array}{c}\% \\
\text { Positive }\end{array}$ & $\begin{array}{c}\text { Mean } \\
\text { Diff. }\end{array}$ & $\begin{array}{l}\text { Median } \\
\text { Diff. }\end{array}$ & $\begin{array}{c}\% \\
\text { Positive }\end{array}$ \\
\hline 1987 & 1,442 & $0.01977^{*}+$ & 0.00000 & $55.98^{*}+$ & $0.02501^{*}+$ & 0.00000 & $53.52 *+$ \\
\hline 1988 & 7,950 & $-0.02901^{*}$ & 0.00000 & $39.62^{*}$ & $0.006686^{*}+$ & 0.00000 & $52.04 *+$ \\
\hline 1989 & 13,851 & $-0.00536^{*}$ & 0.00000 & $45.15^{*}$ & $0.00971^{*}+$ & 0.00000 & $53.29 *+$ \\
\hline 1990 & 20,853 & $-0.01732^{*}$ & 0.00000 & $37.16^{*}$ & $0.00770 *+$ & 0.00000 & $51.46^{*}+$ \\
\hline 1991 & 32,566 & $-0.03242^{*}$ & 0.00000 & $32.02^{*}$ & $0.008631^{*}+$ & 0.00000 & $52.26^{*+}+$ \\
\hline 1992 & 60,162 & $-0.04484^{*}$ & -0.04286 & $27.65^{*}$ & $-0.00454^{*}$ & 0.00000 & $49.02 *$ \\
\hline 1993 & 82,444 & $-0.03832^{*}$ & -0.03009 & $29.99^{*}$ & $-0.00975^{*}$ & 0.00000 & $47.63^{*}$ \\
\hline 1994 & 96,243 & $-0.03637^{*}$ & -0.02431 & $31.51^{*}$ & $-0.01787^{*}$ & 0.00000 & $44.71^{*}$ \\
\hline 1995 & 157,371 & $-0.04133^{*}$ & -0.03736 & $28.60^{*}$ & $-0.02084^{*}$ & 0.00000 & $44.13^{*}$ \\
\hline 1996 & 153,126 & $-0.02990^{*}$ & -0.00280 & $32.47^{*}$ & $-0.01869^{*}$ & 0.00000 & $48.62^{*}$ \\
\hline 1997 & 103,637 & $-0.02894^{*}$ & -0.00063 & $32.60 *$ & $-0.02194^{*}$ & 0.00000 & $42.26^{*}$ \\
\hline 1987-1997 & 729,645 & $-0.03445^{*}$ & -0.01609 & $31.26^{*}$ & $-0.01446^{*}$ & 0.00000 & $45.51^{*}$ \\
\hline
\end{tabular}

possible that the cross-listed options in our sample would have had narrower bid-ask spreads even had they been single listed. Likewise, DPM listing is determined endogenously, and DPM options in our sample might have had narrower spreads even under an open outcry system. In this section, we attempt to address this problem.

\section{A. Analysis of Delisted Options}

An interesting experiment would be to analyze spreads on options before and after multiple listing. As mentioned in Section I, cross-listing began for newly listed options in 1990 for exchange-traded stocks. Previously listed options were not cross-listed until August 1999. Unfortunately, this is outside of our sample period. De Fountnouvelle et al. (2000), analyzing Options Price Reporting Authority data from August and September, 1999, verify that bid-ask spreads did become narrower for stocks that move from single to multiple listing. This suggests that our results cannot be explained by the endogeneity of the listing decision. 


\section{Table VII \\ Differences in Spreads-Designated Primary Marketmaker Versus Trading Crowd}

This table compares spreads on options traded under a DPM with those traded in a traditional trading crowd, controlling for date, option price, the option's own contract volume, aggregate option volume, and implied volatility. Mean and median differences are reported for both quoted and effective bid-ask spreads. Tests were based on a sample of 14,050 pairs of options. A negative number indicates that options traded under a DPM have narrower spreads. An asterisk indicates a $t$-statistic that is significant at the one percent level.

\begin{tabular}{|c|c|c|c|c|c|}
\hline \multirow[b]{2}{*}{ Year } & \multirow[b]{2}{*}{$N$} & \multicolumn{2}{|c|}{ Quoted } & \multicolumn{2}{|c|}{ Effective } \\
\hline & & Mean Diff. & Median Diff. & Mean Diff. & Median Diff. \\
\hline 1987 & 54 & -0.01508 & 0.00000 & -0.02516 & 0.00000 \\
\hline 1988 & 189 & -0.01778 & 0.00000 & 0.008367 & 0.00000 \\
\hline 1989 & 532 & -0.01021 & 0.00000 & -0.00310 & 0.00000 \\
\hline 1990 & 439 & $-0.02399^{*}$ & 0.00000 & -0.00306 & 0.00000 \\
\hline 1991 & 631 & $-0.02991^{*}$ & 0.00000 & 0.008332 & 0.00000 \\
\hline 1992 & 1,089 & $-0.05699^{*}$ & -0.04510 & -0.01097 & 0.00000 \\
\hline 1993 & 1,775 & $-0.04979 *$ & -0.02802 & $-0.01815^{*}$ & 0.00000 \\
\hline 1994 & 2,136 & $-0.03538^{*}$ & -0.00436 & $-0.02163^{*}$ & 0.00000 \\
\hline 1995 & 3,778 & $-0.04173^{*}$ & -0.01718 & $-0.02701^{*}$ & -0.00215 \\
\hline 1996 & 1,746 & $-0.04383^{*}$ & -0.03329 & $-0.03994^{*}$ & -0.02615 \\
\hline 1997 & 1,589 & $-0.03991^{*}$ & -0.03686 & $-0.03555^{*}$ & -0.02344 \\
\hline 1986-1997 & 13,958 & $-0.04031^{*}$ & -0.01252 & $-0.02265^{*}$ & 0.00000 \\
\hline
\end{tabular}

Within our sample, there are several cases of options that were crosslisted but subsequently became single listed when they were delisted by one exchange. To further test whether our results are driven by the endogeneity of the listing process, we compared bid-ask spreads before and after delisting by a competing exchange.

We identified 14 cases of options between August 1991 and May 1996 that were cross-listed on the $\mathrm{CBOE}$ and another exchange and subsequently delisted by the other exchange. In each case, we define the "preevent" period to be the six calendar months preceding the delisting month and the "postevent" period to be the six calendar months after. We then proceed to construct another paired sample, with one observation before and one after the competing exchange's delisting date, with both options on the same underlying stock and matching by option price, contract volume, and aggregate option volume. The resulting sample contained 1,620 matched pairs of options.

In this sample, we found that quoted spreads on the CBOE became wider after being delisted by a competing exchange. The mean change was 0.02277 , which is significantly positive at the one percent confidence level. Likewise, effective spreads became wider, with a mean change of 0.02535 , also a significant increase at the one percent level. 
PANEL A

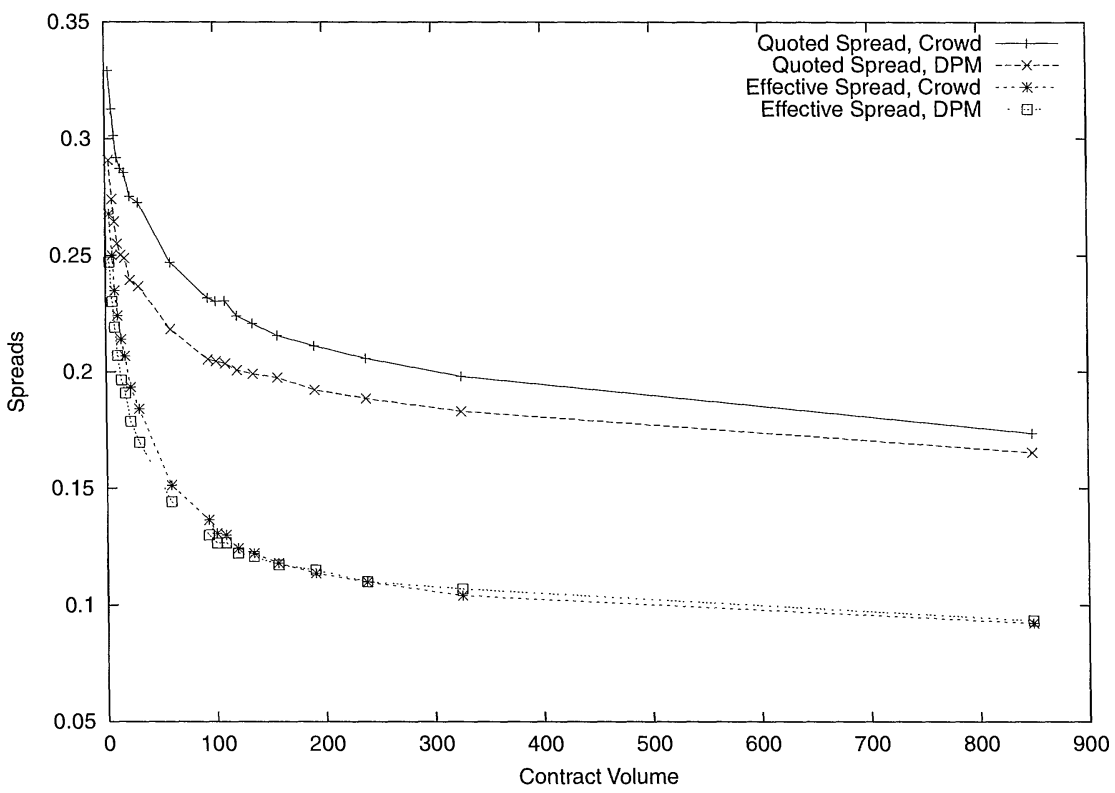

PANEL B

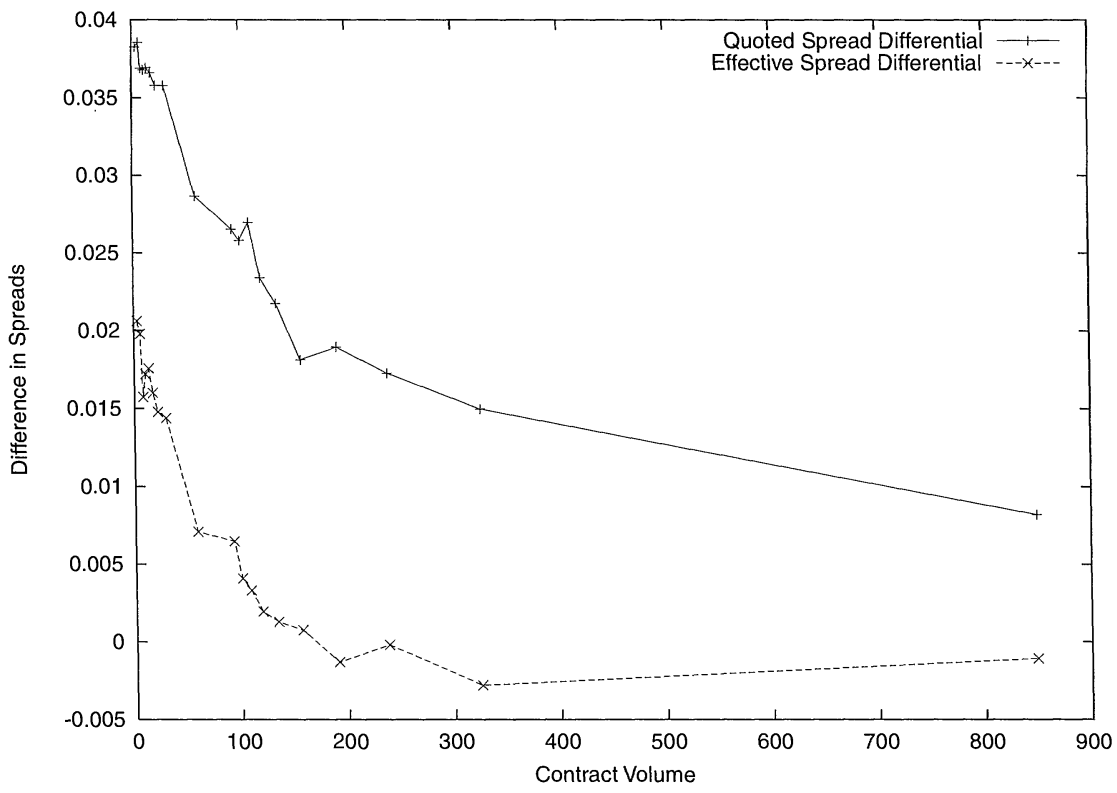

Figure 5. Quoted and effective spreads for options traded under different trading structures, as a function of trading volume. The graph is based on a sample of 729,645 pairs of options, matched according to date, price, contract-specific volume, and total option volume, with one option traded under a DPM and one traded in a traditional crowd. The first 9 points correspond to the bottom 9 volume deciles. The next 10 points correspond to the highest 10 volume percentiles. 


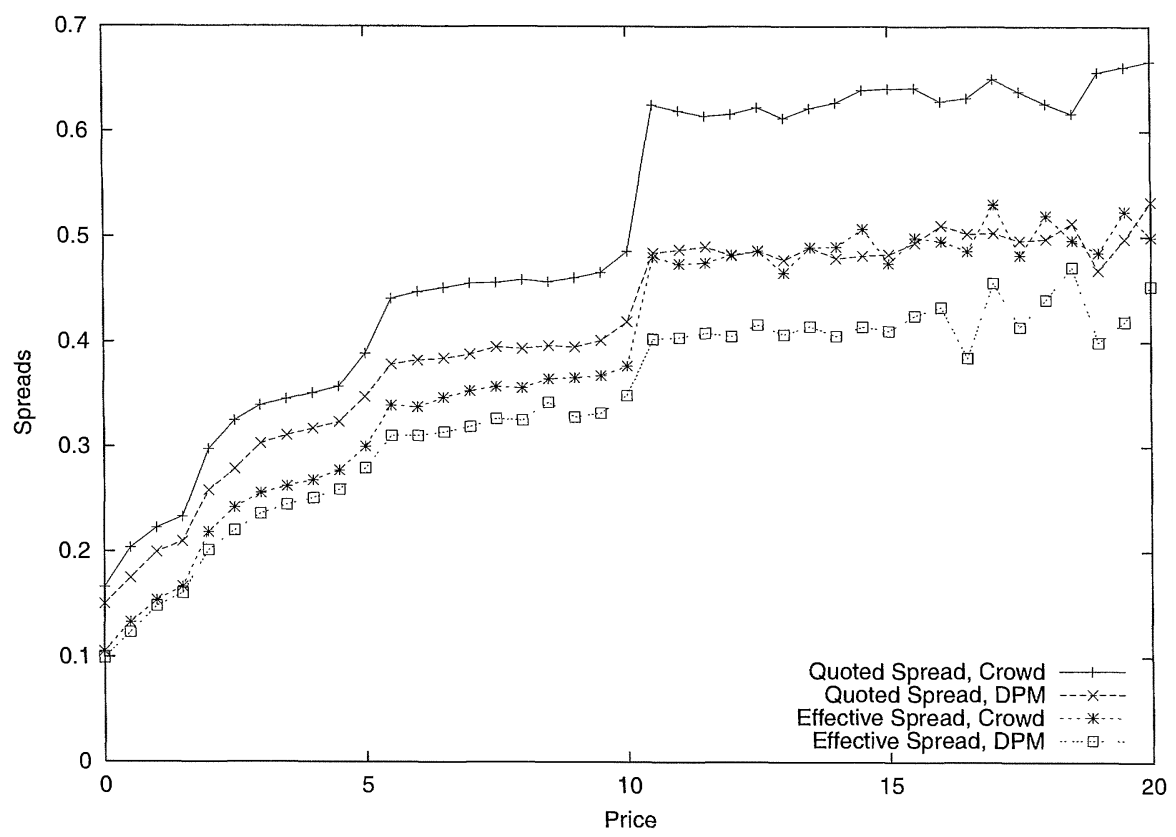

Figure 6. Quoted and effective spreads for options traded under different trading structures, as a function of option price. The graph is based on a sample of 729,645 pairs of options, matched according to date, price, contract-specific volume, and total option volume.

\section{B. Analysis of Listing Decisions}

As a second approach to assessing the impact of endogeneity, we use Probit analysis in an effort to determine what types of stocks were most likely to be selected by multiple exchanges, or most likely to be assigned to a DPM. We then go back in time before 1990 and attempt to identify options most likely to have been cross-listed had it been permitted at the time. These are then paired in a control sample against options that actually were cross-listed. Similarly, we create a control sample of options listed prior to 1987 that have similar characteristics to the options selected for DPM listing after 1987.

Data on initial listing dates were obtained from the CBOE. Our analysis of multiple listing (DPM Listing) is based on listings since January 1990 (November 1987). As independent variables, we use the average daily trading volume, underlying stock price, and the volatility of the underlying stock in the month preceding the listing date. Volatility is calculated as the standard deviation of continuous daily returns. Volume and returns data were obtained from CRSP. In an alternate specification, we also included firm size as an explanatory variable, but found that it was not a significant determinant of multiple listing or DPM listing. 


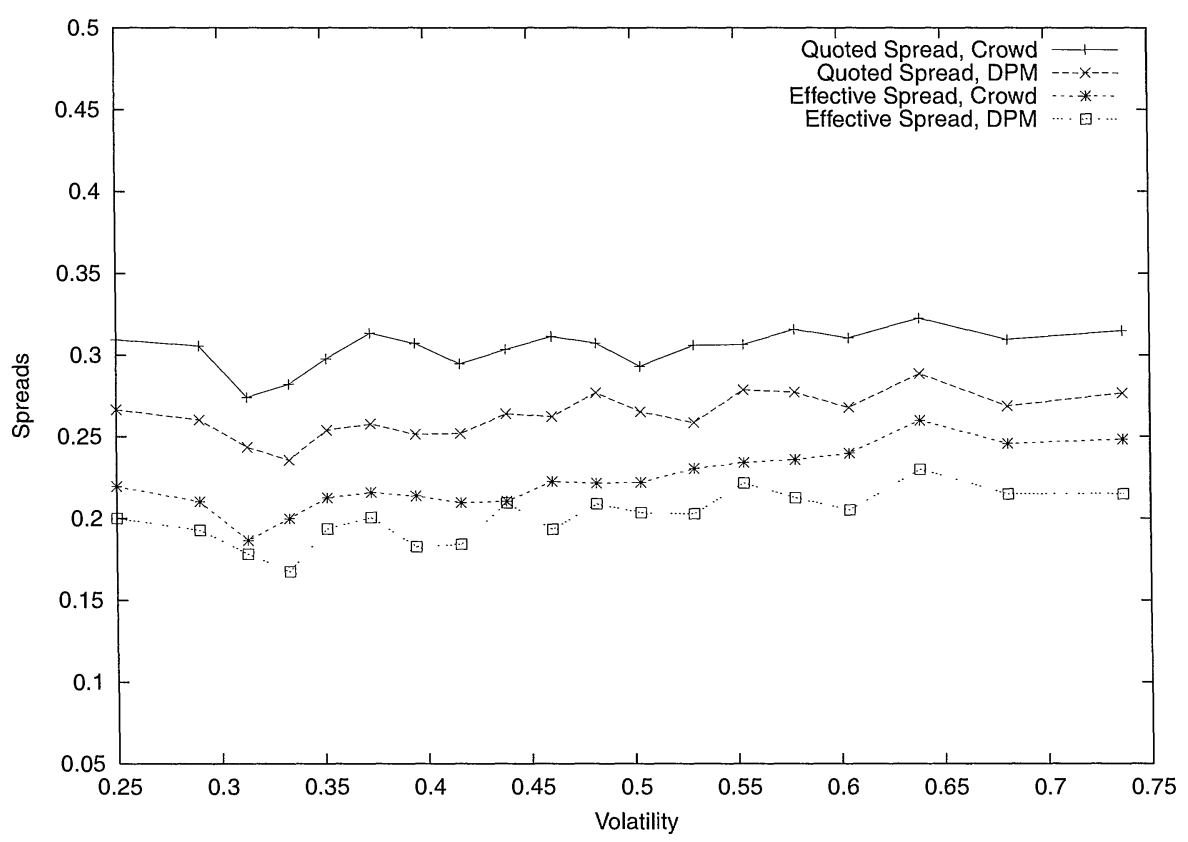

Figure 7. Quoted and effective spreads for options traded under different trading structures, as a function of implied volatility. The graph is based on a sample of 17,562 pairs of options, matched according to date, price, contract-specific volume, total option volume, and implied volatility, with one option traded under a DPM and one traded in a traditional crowd.

Table VIII shows parameter estimates from the probit model

$$
P R(L)=N(Z) \equiv N\left(b_{0}+b_{1} \text { VOLUME }+b_{2} \text { VOLATILITY }+b_{3} \text { PRICE }\right),
$$

where the left-hand side is the probability a CBOE option will be cross-listed (row 1) or the probability it will be listed under a DPM (row 2), $N($ ) is the cumulative normal distribution, VOLUME is the average daily trading volume, VOLATILITY is the standard deviation of daily returns on the underlying stock, and PRICE is the underlying stock price. We find that stocks with higher trading volume, higher volatility, and higher prices are more likely to be multiple listed. Also, stocks with higher volume and lower volatility are more likely to be assigned to a DPM. Stock price appears to play no significant role in the DPM assignment.

The parameter estimates from Table VIII were used to create a control sample of hypothetical multiple listings prior to 1990, and of hypothetical DPM assignments prior to 1987. In each case, two control samples were constructed, based on the predicted probabilities of listing derived from the 
Table VIII

\section{Determinants of Market Structure}

Parameter estimates for a probit model of multiple listing (ML) and DPM listing. The probability of listing is modeled as a function of the average trading volume, stock price, and volatility in the month prior to listing. The ML model is estimated using CBOE option listings after January 1990. The DPM model is estimated using CBOE listings after November 1987. Both samples require that prior data be available in CRSP. Significance levels based on a chi-square test are reported in parentheses.

\begin{tabular}{lcccc}
\hline Model & Intercept & VOLUME & VOLATILITY & PRICE \\
\hline ML & -1.06375 & 0.12624 & 0.43534 & 0.00910 \\
& & $(0.0001)$ & $(0.0035)$ & $(0.0004)$ \\
DPM & -0.03113 & 0.05088 & -0.65099 & 0.00147 \\
& & $(0.0411)$ & $(0.0063)$ & $(0.6778)$ \\
\hline
\end{tabular}

probit models. The first included those stocks with predicted probabilities in the highest third of all stocks. The second included only those with predicted probabilities exceeding one-half. Results were similar for both samples, so only the former are included here.

Table IX shows a comparison between spreads on stocks that had multiplelisted options with those in the control sample. Qualitatively, the results are very similar to those reported in Table IV. This reinforces the claim that our results are not driven by the endogeneity of the listing decision. Similarly Table X compares spreads on DPM options with those on options in the DPM control sample, and the results are similar to those in Table VI.

\section{Conclusion}

In this paper, we have used a matched sample methodology to investigate the extent to which interexchange competition and market structure influence bid-ask spreads in option markets. The analysis is based on pairs of options, matched according to price, volume, and volatility characteristics. The population from which the pairs were drawn includes all stock options traded on the Chicago Board Options Exchange from January 1986 to August 1997. Tick-level data were used to calculate quoted and effective bidask spreads.

After accounting for other factors influencing spreads, we find that multiplelisted options tend to have narrower quoted and effective bid-ask spreads than single-listed options. This result is robust over time, and holds for high priced and low priced options, for high volume and low volume options, and for options on high volatility and low volatility stocks. On average in the entire sample, effective spreads are three cents narrower for multiple-listed 


\section{Table IX \\ Differences in Spreads-Hypothetical Versus Actual Cross-listed Options}

The hypothetical sample is of options that were single listed prior to 1990 , but which, according to a probit model, are likely to have been cross-listed had it been permitted. Mean and median differences are reported for both quoted and effective bid-ask spreads. Tests were based on a sample of 54,083 pairs of options, matched by date, option price, the option's own contract volume, and aggregate option volume. A negative number indicates that the actual multiplelisted options have narrower spreads. An asterisk indicates a $t$-statistic that is significant at the one percent level.

\begin{tabular}{cccccr}
\hline & & \multicolumn{2}{c}{ Quoted } & \multicolumn{2}{c}{ Effective } \\
\cline { 3 - 4 } \cline { 5 - 6 } Year & $N$ & Mean Diff. & Median Diff. & Mean Diff. & Median Diff. \\
\hline 1986 & 1,723 & $-0.01310^{*}$ & 0.00000 & -0.00993 & 0.00000 \\
1987 & 2,478 & $-0.01283^{*}$ & 0.00000 & -0.00481 & 0.00000 \\
1988 & 2,279 & $-0.02110^{*}$ & 0.00000 & -0.00908 & 0.00000 \\
1989 & 2,446 & $0.014073^{*}$ & 0.00000 & 0.002179 & 0.00000 \\
1990 & 2,726 & $-0.03094^{*}$ & 0.00000 & $-0.02195^{*}$ & 0.00000 \\
1991 & 3,516 & $-0.06408^{*}$ & -0.06250 & $-0.04201^{*}$ & -0.02460 \\
1992 & 5,330 & $-0.08160^{*}$ & -0.06250 & $-0.04530^{*}$ & -0.02442 \\
1993 & 5,891 & $-0.07442^{*}$ & -0.06250 & $-0.04660^{*}$ & -0.04073 \\
1994 & 6,393 & $-0.07583^{*}$ & -0.06250 & $-0.05517^{*}$ & -0.05978 \\
1995 & 8,114 & $-0.05323^{*}$ & -0.06250 & $-0.03571^{*}$ & -0.02995 \\
1996 & 7,250 & $-0.04634^{*}$ & -0.05869 & $-0.03770^{*}$ & -0.03630 \\
1997 & 5,937 & $-0.03819^{*}$ & -0.01655 & $-0.03612^{*}$ & -0.02748 \\
$1986-1997$ & 54,083 & $-0.05049^{*}$ & -0.05267 & $-0.03511^{*}$ & -0.02183 \\
\hline
\end{tabular}

options. The difference decreases as trading volume increases, however-for high-volume options, the difference in effective spreads is less than half of one cent. For all subsamples, the difference in effective spreads is smaller than the difference in quoted spreads, suggesting more price improvement for single-listed options.

We also find that over the period 1988-1997, after accounting for other factors influencing spreads, options traded under a Designated Primary Marketmaker (DPM) have narrower quoted spreads than those traded in a traditional open outcry crowd. Prior to 1991, however, effective spreads were actually wider under the DPM. This illustrates that quoted spreads can be misleading. From 1992 to 1997, effective spreads were slightly narrower for options trading under a DPM. Subsample analysis reveals that this result is driven by low-volume options. For the most actively traded options, effective spreads were slightly wider under a DPM. In other words, the Designated Primary Marketmaker structure appears to perform slightly better for lowvolume options, and the traditional crowd appears to be better for highvolume options. 


\section{Table X}

\section{Differences in Spreads-Hypothetical Versus Actual DPM Options}

The hypothetical sample is of options that were listed open outcry prior to November 1987, but which, according to a probit model, are likely to have been assigned to a DPM had it been permitted. Mean and median differences are reported for both quoted and effective bid-ask spreads. Tests were based on a sample of 42,785 pairs of options, matched by date, option price, the option's own contract volume, and aggregate option volume. A negative number indicates that the actual DPM options have narrower spreads. An asterisk indicates a $t$-statistic that is significant at the one percent level.

\begin{tabular}{|c|c|c|c|c|c|}
\hline \multirow[b]{2}{*}{ Year } & \multirow[b]{2}{*}{$N$} & \multicolumn{2}{|c|}{ Quoted } & \multicolumn{2}{|c|}{ Effective } \\
\hline & & Mean Diff. & Median Diff. & Mean Diff. & Median Diff \\
\hline 1987 & 45 & -0.05309 & 0.00000 & 0.00004 & 0.00000 \\
\hline 1988 & 1,022 & $-0.04042^{*}$ & -0.00156 & 0.00513 & 0.00000 \\
\hline 1989 & 1,760 & $-0.02782^{*}$ & 0.00000 & -0.00443 & 0.00000 \\
\hline 1990 & 2,543 & $-0.03909^{*}$ & 0.00000 & $-0.01162^{*}$ & 0.00000 \\
\hline 1991 & 3,641 & $-0.04724^{*}$ & -0.01157 & -0.00355 & 0.00000 \\
\hline 1992 & 5,460 & $-0.06621^{*}$ & -0.05300 & $-0.02177^{*}$ & 0.00000 \\
\hline 1993 & 5,603 & $-0.06608^{*}$ & -0.06250 & $-0.03677^{*}$ & -0.01058 \\
\hline 1994 & 5,839 & $-0.05951^{*}$ & -0.06250 & $-0.03473^{*}$ & -0.02200 \\
\hline 1995 & 6,275 & $-0.04832^{*}$ & -0.06250 & $-0.02635^{*}$ & -0.00556 \\
\hline 1996 & 6,111 & $-0.04087^{*}$ & -0.03481 & $-0.02482^{*}$ & -0.01036 \\
\hline 1997 & 4,486 & $-0.03333^{*}$ & -0.01240 & $-0.03002^{*}$ & -0.01667 \\
\hline 1987-1997 & 42,785 & $-0.05015^{*}$ & -0.03964 & $-0.02394^{*}$ & 0.00000 \\
\hline
\end{tabular}

\section{REFERENCES}

Amin, Kaushik I., and Charles M. C. Lee, 1997, Option trading, price discovery, and earnings news dissemination, Contemporary Accounting Research 14, 153-192.

Ap Gwilym, Owain, Mike Buckle, and Stephen Thomas, 1997, The intraday behavior of bid-ask spreads, returns, and volatility for FTSE-100 stock index options, Journal of Derivatives 4 (Summer), 20-32.

Battalio, Robert, Brian Hatch, and Robert Jennings, 2000, Does a national market system exist for U.S. exchange-listed equity options?: An analysis of multiple-traded equity options, Working paper, University of Notre Dame.

Berkman, Henk, 1993, The market spread, limit orders, and options. Journal of Financial Services Research 6, 399-415.

Chan, Kalok, Y. Peter Chung, and Herb Johnson, 1995, The intraday behavior of bid-ask spreads for NYSE stocks and CBOE options, Journal of Financial and Quantitative Analysis 30, 329-346.

De Fountnouvelle, Patrick, Raymond P. H. Fishe, and Jeffrey H. Harris, 2000, The behavior of bid-ask spreads and volume in options markets during the listings competition in 1999, Working paper, U.S. Securities and Exchange Commission.

Grossman, Sanford J., and Merton H. Miller, 1988, Liquidity and market structure, Journal of Finance 43, 617-633.

Madhavan, Ananth, 1988, An empirical model of competitive dealer markets, Doctoral dissertation (Chapter III), Cornell University.

Neal, Robert, 1987, Potential competition and actual competition in equity options, Journal of Finance 42, 511-531.

Neal, Robert, 1992, A comparison of transaction costs between competitive market maker and specialist market structures, The Journal of Business 65, 317-334.

Wang, Elizabeth, 2000, Competition among exchanges: Does multiple listing affect trading costs on options markets?, Working paper, University of Chicago. 
http://www.jstor.org

\section{LINKED CITATIONS \\ - Page 1 of 1 -}

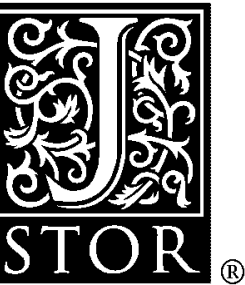

You have printed the following article:

Competition, Market Structure, and Bid-Ask Spreads in Stock Option Markets

Stewart Mayhew

The Journal of Finance, Vol. 57, No. 2. (Apr., 2002), pp. 931-958.

Stable URL:

http://links.jstor.org/sici?sici=0022-1082\%28200204\%2957\%3A2\%3C931\%3ACMSABS\%3E2.0.CO\%3B2-V

This article references the following linked citations. If you are trying to access articles from an off-campus location, you may be required to first logon via your library web site to access JSTOR. Please visit your library's website or contact a librarian to learn about options for remote access to JSTOR.

\section{References}

\section{The Intraday Behavior of Bid-Ask Spreads for NYSE Stocks and CBOE Options}

Kalok Chan; Y. Peter Chung; Herb Johnson

The Journal of Financial and Quantitative Analysis, Vol. 30, No. 3. (Sep., 1995), pp. 329-346.

Stable URL:

http://links.jstor.org/sici?sici=0022-1090\%28199509\%2930\%3A3\%3C329\%3ATIBOBS\%3E2.0.CO\%3B2-S

\section{Liquidity and Market Structure}

Sanford J. Grossman; Merton H. Miller

The Journal of Finance, Vol. 43, No. 3, Papers and Proceedings of the Forty-Seventh Annual Meeting of the American Finance Association, Chicago, Illinois, December 28-30, 1987. (Jul., 1988), pp. 617-633.

Stable URL:

http://links.jstor.org/sici?sici=0022-1082\%28198807\%2943\%3A3\%3C617\%3ALAMS\%3E2.0.CO\%3B2-G

\section{Potential Competition and Actual Competition in Equity Options}

Robert Neal

The Journal of Finance, Vol. 42, No. 3, Papers and Proceedings of the Forty-Fifth Annual Meeting of the American Finance Association, New Orleans, Louisiana, December 28-30, 1986. (Jul., 1987), pp. 511-531.

Stable URL:

http://links.jstor.org/sici?sici=0022-1082\%28198707\%2942\%3A3\%3C511\%3APCAACI\%3E2.0.CO\%3B2-H 